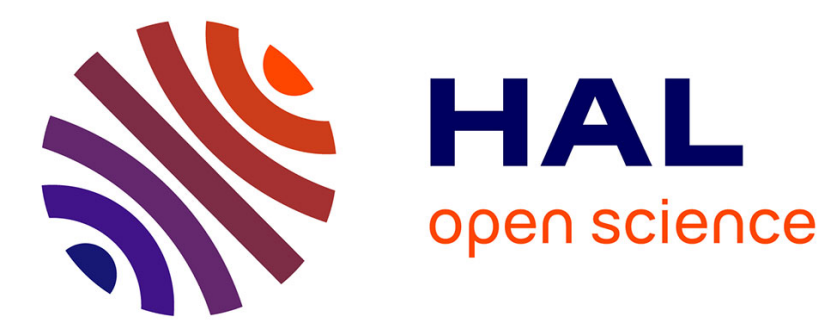

\title{
Modeling the Odor Generation in WWTP: An Integrated Approach Review
}

Fabio Carrera-Chapela, Andres Donoso-Bravo, Gonzalo Ruiz-Filippi, José A. Souto

\section{- To cite this version:}

Fabio Carrera-Chapela, Andres Donoso-Bravo, Gonzalo Ruiz-Filippi, José A. Souto. Modeling the Odor Generation in WWTP: An Integrated Approach Review. Water, Air, and Soil Pollution, 2014, 225, pp.1 - 15. 10.1007/s11270-014-1932-y . hal-01086002

\section{HAL Id: hal-01086002 https://hal.inria.fr/hal-01086002}

Submitted on 1 Dec 2014

HAL is a multi-disciplinary open access archive for the deposit and dissemination of scientific research documents, whether they are published or not. The documents may come from teaching and research institutions in France or abroad, or from public or private research centers.
L'archive ouverte pluridisciplinaire HAL, est destinée au dépôt et à la diffusion de documents scientifiques de niveau recherche, publiés ou non, émanant des établissements d'enseignement et de recherche français ou étrangers, des laboratoires publics ou privés. 


\section{Modeling the Odor Generation in WWTP: An Integrated Approach Review}

\section{Fabio Carrera-Chapela, Andres Donoso- Bravo, José A. Souto \& Gonzalo Ruiz- Filippi}

Water, Air, \& Soil Pollution An International Journal of Environmental Pollution

ISSN 0049-6979

Volume 225

Number 6

Water Air Soil Pollut (2014) 225:1-15 DOI 10.1007/s11270-014-1932-y
Volume 225, no. 4 (2014)

ISSN 0049-6979

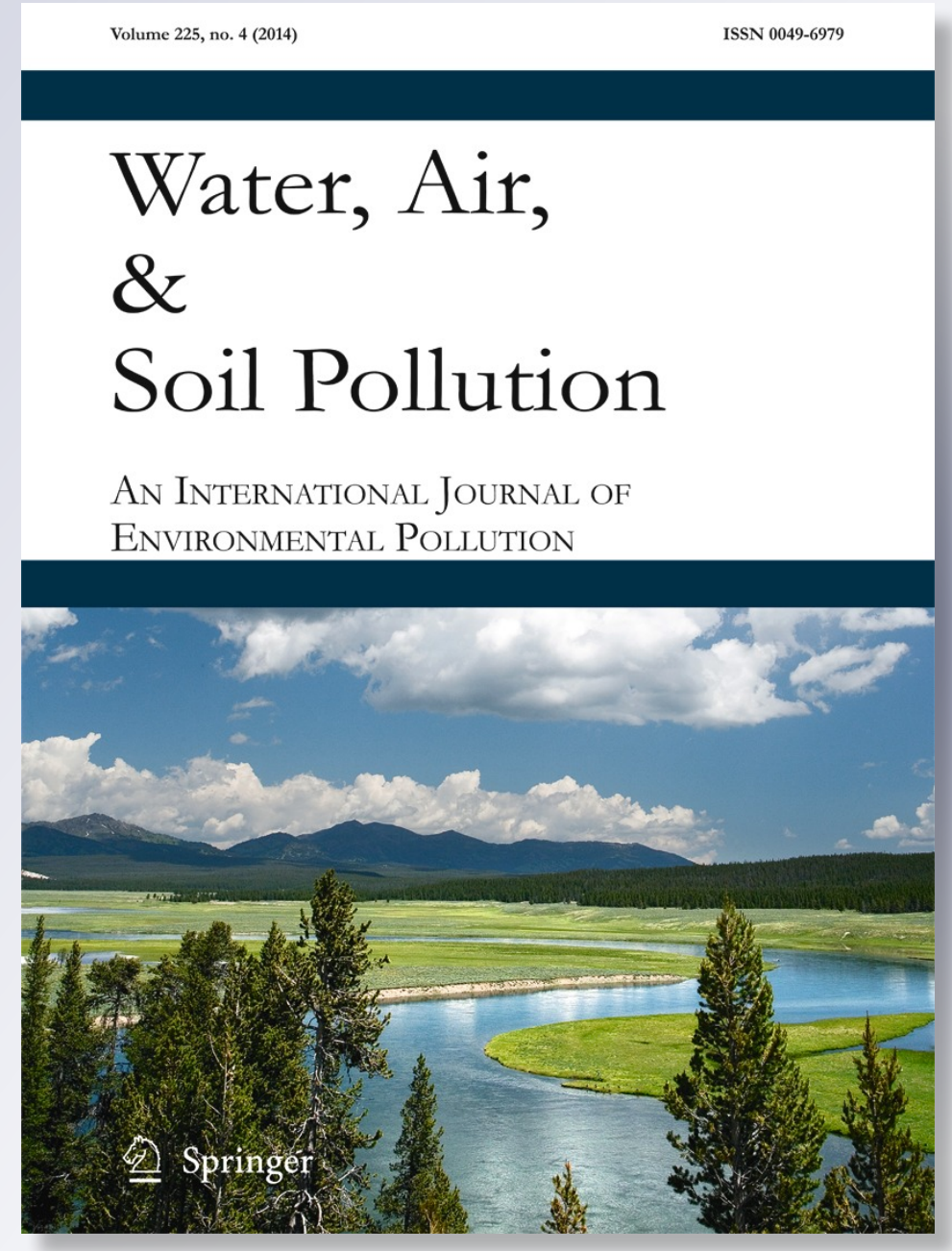

望 Springer 
Your article is protected by copyright and all rights are held exclusively by Springer International Publishing Switzerland. This eoffprint is for personal use only and shall not be self-archived in electronic repositories. If you wish to self-archive your article, please use the accepted manuscript version for posting on your own website. You may further deposit the accepted manuscript version in any repository, provided it is only made publicly available 12 months after official publication or later and provided acknowledgement is given to the original source of publication and a link is inserted to the published article on Springer's website. The link must be accompanied by the following text: "The final publication is available at link.springer.com". 


\title{
Modeling the Odor Generation in WWTP: An Integrated Approach Review
}

\author{
Fabio Carrera-Chapela • Andres Donoso-Bravo • \\ José A. Souto • Gonzalo Ruiz-Filippi
}

Received: 2 August 2013 / Accepted: 10 March 2014

(C) Springer International Publishing Switzerland 2014

\begin{abstract}
Nuisance odors generation from waste and wastewater treatment plants are a cause of public discomfort and complaints. This situation impairs the air quality and represents a growing social and public health problem, especially in developing countries. Several modeling approaches have been developed and successfully implemented in the frame of a wastewater treatment plant for both the biological treatment and physicochemical processes. The mathematical modeling of the odor generation process is still considered a quite complex issue, mainly due to the fact that olfactory nuisance can be caused by many different chemical compounds and the perception of odors is influenced by subjective thresholds. Moreover, the impact of odor sources on air quality is highly conditioned by complex atmospheric dispersion processes. This review presents a critical state-of-art and
\end{abstract}

INRIA-Chile. Communication and Information Research and Innovation Center (CIRIC). Avenida Apoquindo 2827, Piso 12, Las Condes, Santiago, Chile.

F. Carrera-Chapela $(\varangle) \cdot$ A. Donoso-Bravo .

G. Ruiz-Filippi

Escuela de Ingeniería Bioquímica, Pontificia Universidad

Católica de Valparaso, General Cruz 34, Valparaíso, Chile

e-mail: fabio.carrera@usc.es

F. Carrera-Chapela $\cdot$ J. A. Souto

Department of Chemical Engineering,

School of Engineering, University of Santiago

de Compostela, Rúa Lope Gómez de Marzoa s/n,

15782 Santiago de Compostela, Spain assessment where information related to odor emissions impact studies as well as modeling applications are compiled and discussed.

Keywords Wastewater treatment plants · Odor characterization · Odor emissions · Process modeling . Air quality

\section{Introduction}

Biological treatment and stabilization is widely used to reduce the organic matter and nutrient concentration of waste and wastewater, thus minimizing their environmental impact. One of the most important concerns, if not the most, about biological treatment is the generation of malodorous compounds (Liu et al. 2010). Historically, unpleasant odors have been considered as signals or warning indicators about human potential health risks, as well as a significant factor of life quality deterioration. In recent years, wastewater treatment plants odor have been the target of several community complaints, especially neighbors close to those facilities. The formation of these unpleasant odors proceeds from microbial action during the organic matter decomposition processes, i.e., food, animal scums, and organic compounds oxidation (Kalantar et al. 2002), mainly when anaerobic conditions are reached.

In regards to the chemical nature of the odors, most of unpleasant environmental odors are related 
with sulfide-derived compounds. Recently, volatile organic sulfur compounds (VOSCs) have been studied because of their different role in the global sulfur cycle and also in odor formation. The most interesting compounds in this family are methanethiol (MT) and dimethyl sulphide (DMS) (Bentley and Chasteen 2004). MT contributes to the characteristic odor of several cheeses, but in unpleasant way by the action of periodontal bacterial Porphyromonas gingivalis, forming halitosis and broccoli store odor. However, odors produced by short-chain dialkyl-sulfurs (methyl to propyl) are less unpleasant than the correspondents thiols, also named mercaptans (Challenger 1959). Both, DMS and MT, contribute to the characteristic sulfur odor of cooked cabbage (Kalantar et al. 2002).

Control odor strategies depend on the knowledge of the interactions between its chemical components and their dilution in the atmosphere after being emitted. Hydrogen sulfide is a common compound in the atmospheric emissions from wastewater treatment plants (WWTP) but, if other odor species (VOSCs) are also emitted, the final odor effect will be modified by the synergetic action of these organic volatile substances, changing the typical odor of rotten egg to another one more or less unpleasant (Laing et al. 1994). For this reason, it is quite complicated to predict the odor characteristics of gases mixtures even though their exact chemical composition could be determined. From the beginning of the twentieth century, plenty of research have been done in regards to the effects of several different odor constituents; however, there is little research related with mixtures odor of more than two substances (Laing et al. 1994).

Mathematical modeling aims to represent the main aspects of biological, physical, and/or chemical process that compose a specific system. Its use enables a better understanding of the process, being important for control strategies, optimization, and process monitoring (Donoso-Bravo et al. 2011). Big efforts have been lately done in the development of mathematical models of the biological processes that take place in WWTP, i.e., both the aerobic oxidation process and the anaerobic degradation of solid waste (Vollertsen et al. 2008). However, these models do not include the meteorological behavior which would be necessary in order to provide accurate information for air quality emissions studies related with odor dispersion impact in the surrenders. Considering the impact and the benefits of modeling techniques application in current industrial sectors as well as the fact that the available information to carry out an integrated study of odor impact from WWTPs is sparse in the literature, this review aims to collect, in a critical way, the information regarding the mathematical approaches used for odors generation and propagation from a WWTP.

\section{WWTP Odor Generation}

Nowadays, the concern about odor generation in wastewater treatment is significant. The main stages of the whole process in which the odor generation has been identified are wastewater collection, transfer, and treatment, establishing that during the wastewater transfer from the collection systems to the treatment plant, significant amount of unpleasant odor substances can be emitted from manhole, joints, and terminations, specially if anoxic conditions are developed (Gostelow and Parsons 2000; Gostelow et al. 2001; Dincer and Muezzinoglu 2007).

Among the emitted compounds, organic gases, inorganic gases, and steams can be found; many of these gases proceed from the anaerobic decomposition of organic matter with sulfur and nitrogen content. Yang and Hobson (2000) reported that hydrogen sulfide, carbon dioxide, and methane are the main atmospheric emissions from WWTP; although the precursor of the characteristic emission odor in the WWTP is the hydrogen sulfide.

Young et al. (2013) and Muezzinoglu (2003) have identified other compounds highly unpleasant in the emissions from the holes on the collection system: mercaptans, organic sulfur substances, and amines. Organic acids and ketones have been also found as a consequence of industrial discharges. An interesting classification of the emission sources from a WWTP was done by Gostelow et al. (2001), as follows:

- Sources that promote mass transfer when the odor substances have already been formed, i.e., aerated grit separator, activated sludge treatment.

- Sources where new odorants form, i.e., primary/secondary sedimentation, thickening tanks.

The main odor sources in the wastewater process may be located at the plant entrance, if the water contains septic conditions, and/or during the sludge treatment where anaerobic conditions generate 
new odorants as an inherent part of the bioprocess (Hobson 1995). Also, other process units as the primary settlers can stimulate the emission of substances previously generated in the plant entrance because of their calm flow conditions. Moreover, if the sludge purge is not enough to remove anaerobic activity, new odorants substances could be formed.

Capelli et al. (2009) reported in a research of odor emissions for 17 WWTP in Italy, that mean emission values are independent of the plant size, concluding that odor emissions is a common issue in this treatment. Their results show that the main odor source is the first treatment stage, decreasing while the process goes forward, pointing that collecting system has more influence in odor formation than treatment stages. Stuetz and Frechen (2001) carried out a quiz to the plant operators in France and Germany in order to identify the process units where more odors are generated, which is shown in Fig. 1.

These subjective results obtained by Stuetz and Frechen (2001) are in agreement with the olfatometric measures carried out by Capelli et al. (2009), who identified primary treatment and sludge treatment as the main odor sources.

Recent results obtained by Pérez et al. (2012) are also in agreement with previous research, since primary and sludge treatments are identified as the main odor sources. Nevertheless, in terms of odor flow $\left(\mathrm{OU}_{E} \mathrm{~h}^{-1}\right)$, their results show a more uniform odor distribution, including the biological aerobic reactor, which suggests that the odor emission rate in terms of mass flow is more homogeneous than the concentration of the odor source.

Smet et al. (1999) demonstrated that the WWTP odor emissions are related with VOSCs and hydrogen sulfide produced during anaerobic phases. The odor threshold values of these substances are very low, which means that low concentrations can generate highly unpleasant odor level. In this context, VOSCs precursors in WWTP along the sludge digestion process line are amino acids that conform proteins containing sulfur, as methionine $\left(\mathrm{C}_{5} \mathrm{H}_{11} \mathrm{NO}_{2} \mathrm{~S}\right)$ and cysteine $\left(\mathrm{C}_{3} \mathrm{H}_{7} \mathrm{NO}_{2} \mathrm{~S}\right)$. The methionine presents several degradation routes under different conditions to produce MT, DMS, or hydrogen sulfide. On the other hand, the cysteine only produces hydrogen sulfide under anaerobic conditions (Du and Parker 2012).

This complex composition of odorous emissions was confirmed by Lebrero et al. (2013) who, after an assessment of the sludge handling activities, identified not only sulphur reduced compounds but also aromatics, terpenes, aldehydes, and volatile fatty acids. According to that study, the dynamics of odorant formation are mainly governed by the sludge anaerobic fermentation and, more specifically, by hydrolysis and acidogenesis.

\section{Odor Measure and Estimation}

The odor response is a very subjective and difficult to predict issue since it depends on the detection response for each person. The main problem is that the odor is a result of many different odorants substances

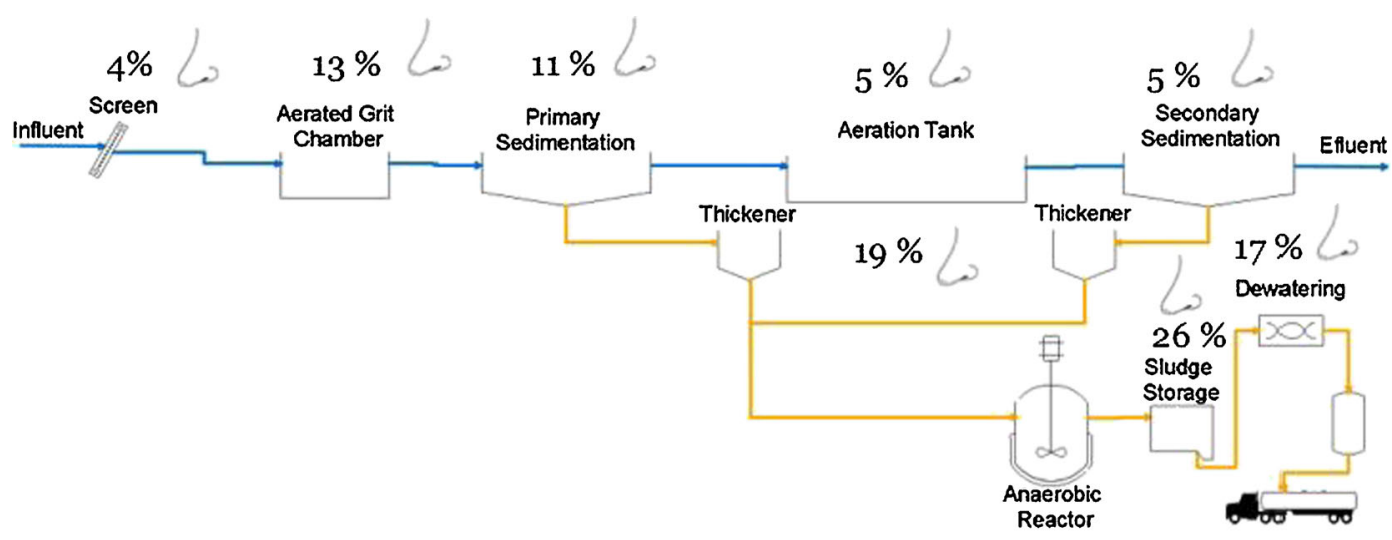

Fig. 1 Odor sources identified and contribution to odor emission in France and Germany WWTP facilities adapted from Stuetz and Frechen (2001) 
and their interaction. This odorants interaction, whose principles are still unclear, influences the odor perception (Gostelow and Parsons 2000). It is necessary, though, to distinguish between odorants and odors. The odorant is the responsible compound that actually generates an odor. On the other hand, the odor is the perceived effect when the odorant has been detected and interpreted by a sensory system. This interaction between the odorant properties and the odor generated is not very clear due to the lack of theoretical knowledge of our olfactory system (Gostelow et al. 2001).

Lebrero et al. (2011) presented an exhausted odor assessment and management review where a number of studies about of odor analysis, classified in sensory, chemical, and online analysis, are evaluated.

Many attempts have been made in order to establish a correlation between the odor concentration, expressed as odor units $\left(\mathrm{OU}_{E} \mathrm{~m}^{-3}\right)$ or odor intensity, with the actual chemical concentration for several nuisance compounds (Gostelow et al. 2001; Hobbs et al. 2002; Lacey et al. 2004; van Thriel et al. 2006; Tsai et al. 2008; Lehtinen and Veijanen 2011). Volatile organic compounds (VOCs), hydrogen sulfide, VOSCs, and ammonia have been the focus of the studies due to their known unpleasant odor and irritation character. It has been demonstrated that the relationship between odor units and chemical concentration follows an exponential function and may be expressed by the Steven's law, as follows (Ferreira 2012):

$C_{O U, i}=k_{i} \cdot C_{i}^{n}$

where

$\begin{array}{ll}C_{O U, i}: & \text { Odor concentration of } i\left(\mathrm{OU}_{E} \mathrm{~m}^{-3}\right) . \\ k_{i}: & \begin{array}{l}\text { Proportional parameter of } i \\ \left(\mathrm{OU}_{E} \mathrm{ppm}^{-1}\right) .\end{array} \\ n: & \begin{array}{l}\text { Exponential parameter for } i \\ \text { (dimensionless). }\end{array} \\ C_{i}: & \text { Chemical concentration of } i(\mathrm{ppm}) .\end{array}$

Steven's law (Eq. 1) establishes an exponential relationship between the hydrogen sulfide concentration and the odor intensity/concentration. Both the proportional and exponential parameters must be carefully calibrated in each case. This expression works well and it is meaningful for a range outside of 0.4-0.6 ratios for binary mixtures because inside this range it overestimates of the actual values (Ferreira 2012).

Steven's law has shown good results for odor estimation in sewage and wastewater treatment plants using hydrogen sulfide chemical concentration as an indicator, establishing an exponential relationship between the hydrogen sulfide concentration and the odor intense/concentration (Gostelow et al. 2001; McGinley and Sensory 2008; Lehtinen and Veijanen 2011). An important drawback of this expression is that this relationship cannot be used for other indicator compounds since the prediction accuracy decreases compared the $\mathrm{H}_{2} \mathrm{~S}$ case. For instance, ammonia does not present an apparent relation as a consequence that it preferentially occupied sensor receptor cell sites more than other odorants, producing a constant stimulus and leading to alter the olfactory acuity (Tsai et al. 2008). Furthermore, there are no conclusive results about the performance and interaction, within the emissions from WWTP facilities, for other odorant compounds such as reduced sulfur.

\subsection{Automatic Odor Measurement: Electronic Nose}

It is important to use accurate odor emission rate in atmospheric dispersion models and in setback distance formulas. Due to the lack of data, none of the existing models consider diurnal or seasonal variations in odor emission rates and the use of the mean value may result in great uncertainty in the assessed results (Romain et al. 2013).

Standard odor measurement methods (Committee European Normalization C 2003) are based in subjective procedures using human panels and dynamic olfactometer. Nowadays, new electronic measure devices have been developed in order to achieve better accuracy, lower detection threshold, and response to different chemical species. These sensors are mainly made of metal oxides, conducting polymers, and catalytic metals. The relative responses between the sensors can be used to produce a unique odor profile or fingerprint; then, any sample may be further analyzed against the odor fingerprint, using pattern recognition techniques and/or neural network algorithms (Stuetz et al. 1999).

The array sensor shown in Fig. 2 represents the typical behavior of an electronic nose (e-nose). The device is composed by an array of different serial transducers, each one specific to a particular organic 
Fig. 2 Odor-intense response in an array sensor transducer (adapted from Persaud and Dodd (1982)

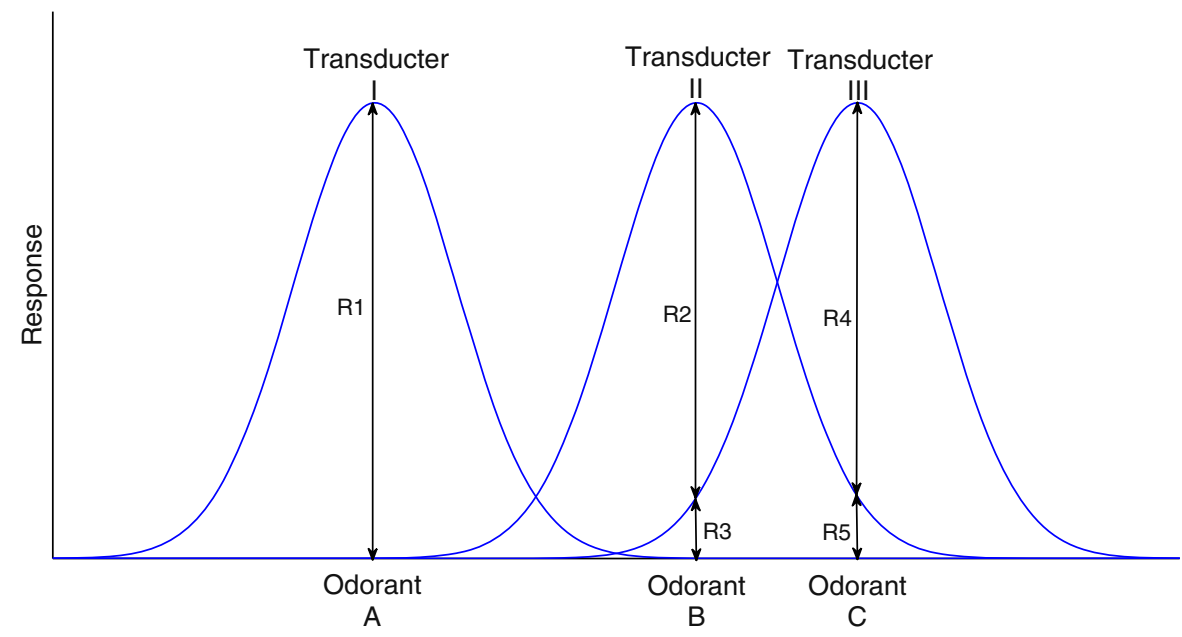

recognize an odor pattern for an specific process, but can also interfere with other substances. One solution could be installing of parallel e-noses with different recognition patterns, which could transmit a better odor profile (Pinheiro et al. 2002).

Nevertheless, e-noses cannot provide high accuracy at very low concentrations as occurs with the main odorants, such as $H_{2} S$ (Dentoni et al. 2012). Moreover, these devices are developed with specific sensor arrays in order to be sensitive to specific chemical compounds present in the odor pattern emitted from different industrial activities (Albert et al. 2000; Arshak et al. 2004).

\subsection{Odor Estimation}

The odor estimation is necessary to predict emission rate to the atmosphere of a number of odor substances by using activity parameters of the entire plant or process unit (fuel consumption, raw material rate, etc.). Several governmental guides provide procedures to estimate emission values applied to wastewater treatment plants (USEPA 1997; AUEPA 1999; NSWEPA 2001). Particularly, National Pollutant Inventory of AUEPA (1999) describes different methods, from the most to the less accurate as follows:

1. Sampling or direct measure: quantifies the associated unit emission, with high cost.

2. Mass balance: identifies the input and output amount of the odor substance referred to a control volume.

3. Fuel analysis and other engineering calculations: empirical equations based on mass transfer and (2010). The high selectivity of these sensors allows to 
liquid-gas equilibrium. Its complexity increases as more unit processes are involved.

4. Emissions factors (EFs): selecting the adequate EFs, emissions rates from activity process parameters are calculated. Generally, EFs are collected from a large database with similar emissionsprocesses.

Environmental Protection Authority of New South Wales (NSWEPA 2001) also establish that EFs should be used when either no other information is available or when it is demonstrated that the generated emissions are negligible. Therefore, although this method is the less accurate, it is the most used one in odor emissions estimation.

An emission factor is a representative value of the total emitted amount rate directly released to the atmosphere and it is related with the activity/process where it is generated. Also, it can be applied when there is no measure equipment to determine the actual emission amount (Calbó and Baldasano 1995). The EFs are used according to Eq. 2. They are a very helpful method because of its simplicity, allowing the calculation of atmospheric emissions from many different sources (point, area, or volume) as described in AP-42 document (EPA 1995),

$E_{i j}=A_{i j} \cdot E F_{i j}$

where,

$A_{i j}$ : Activity parameter of process $i$ which produces pollutant emission $j\left(\mathrm{~kg} \mathrm{~kg}^{-1}\right.$ of process product).

$E F_{i j}$ : Emission factor of pollutant $j$ for process $i$ ( $\mathrm{kg} \mathrm{kg}^{-1}$ of process product).

$E_{i j}$ : Atmospheric emission rate for pollutant $j$ by process $i\left(\mathrm{~kg} \mathrm{day}^{-1}\right)$.

In many cases, EFs are obtained through measured data and assuming long operational time process representative and linear behavior between the emissions and the process activity in a normal process operation range.

During the last years, the scientific community has developed some mathematical tools to estimate the air emissions in WWTP. For instance, WATER9 model (USEPA 2001) includes a large database of physical and chemical properties for VOCs that are present in wastewater during its treatment (Maïzi et al. 2010). Likewise, TOXCHEM ${ }^{\odot}$ includes a better user interface, following the same principles as WATER9 (Martin 2007).

Unfortunately, EFs-based methods appear to be unsuitable to evaluate WWTP control strategies for several reasons. Flores-Alsina et al. (2011) explained that these methods are based on steady-state calculations, without taking into account the wastewater treatment dynamics due to common disturbances. Therefore, it is not possible to consider how changes in the influent load (daily, weekly, and seasonal), temperature (winter/summer), and operating conditions (dissolved oxygen (DO), solids retention time (SRT), and chemical oxygen demand/nitrogen ratio $(\mathrm{COD} / \mathrm{N})$ ) influence the air emissions. Furthermore, some of those estimations are focused on particular wastewater sections/ compounds/technologies, and they do not consider the whole treatment system. On the other hand, these approaches tend to overestimate the emissions rates as a consequence of the misuse of the mass transfer coefficients during regular steady-state operations and underestimate them under unsteady overload conditions. For instance, these models do not include the temperature dependence, which may be a key factor in WWTP operation.

Therefore, unsteady operation of WWTP units must be considered to obtain a realistic estimation of their odor emissions. A significant improvement of the EA use would be the application of some dynamic modeling method for each process unit.

\section{Modeling of Odor-Potential Produced in WWTP Process Units}

\subsection{Activated Sludge Reactor}

The activated sludge reactor is an aerated oxidation tank where the organic matter and nitrogen contained in the wastewater is degraded by microbial action. There are different microbial populations present in the reactor according to the different substrates utilization. The main populations are the aerobic heterotrophic bacteria (decompose organic carbon source into $\mathrm{CO}_{2}$ ), anoxic heterotrophic bacteria (decompose organic carbon source into $\mathrm{CO}_{2}$ and $\mathrm{NH}_{4}$ ), and aerobic autotroph bacteria (decompose $\mathrm{NH}_{4}$ into nitrite/nitrate using $\mathrm{CO}_{2}$ as carbon source) (Henze et al. 1987).

The activated sludge model 1 (ASM1) was developed by Henze et al. (1987) in order to describe 
the biological behavior of activated sludge reactor and it is based in the COD mass balance for the organic matter transformation. Subsequent modifications of this model are ASM2 (Henze et al. 1999), ASM3 (Gujer et al. 1999), and modified ASM3 (Zhou et al. 2013). These models basically included hydrolysis, heterotrophic organisms (denitrification), and autotrophic organisms processes (nitrification) to the original model.

In regards to the odor generation, none of these models include individual composition of some important odorant compounds. For instance, during the particulate organic matter hydrolysis, several odor precursors like PAHs, VOCs, VOSCs, or VFA may be generated, but they are not specifically considered by ASM models; therefore, a crucial part of the odor generation is missing.

However, there are several studies where odor emission rates from the activated sludge reactor have been measured and identified (Gostelow et al. 2001; Sironi et al. 2006; Jeon et al. 2009; Zarra et al. 2009; Stellacci et al. 2010). Particularly, Stellacci et al. (2010) pointed that this process unit significantly contributes to the atmospheric odor emission, and a better understanding of odor compounds production mechanisms should be included into the process unit model. These emissions are mainly produced by the stripping action, i.e., the desorption of gas compounds from the liquid media, induced by aeration bubbles for the aerobic microorganisms.

\subsection{Anaerobic Reactor Modeling}

The anaerobic treatment consists in the degradation of the organic matter contained in the influent into biogas $\left(\mathrm{CH}_{4}\right.$ and $\left.\mathrm{CO}_{2}\right)$ under free oxygen conditions. The whole process is commonly represented as several steps performed by different microbial population that establish a symbiosis relationship (Batstone et al. 2002). A simplified scheme of the whole process is described in Siegrist et al. (2002).

The anaerobic digestion process has been widely studied from the beginning of 70s using mathematical modeling to describe the process behavior. DonosoBravo et al. (2011) described the different models developed in anaerobic digestion, pointing a better understanding in the microbiology process knowledge. The anaerobic digestion model (ADM1) published by Batstone et al. (2002) is the most popular and used model so far. This general model and its modifications related to specific situations have been widely used and validated in many industrial reactors (Batstone and Keller 2003), i.e., odorants compounds generation (Parker and $\mathrm{Wu}$ 2006). Other applications of the ADM1 model to advanced anaerobic digestion are described in Parker (2005). Many models based on the ADM1 have been developed, adding new process to explain specific system conditions or looking for better results in certain operational variables (Batstone et al. 2006). There are also some simplified models that still keep most of the variability of the system. This is the case of the model developed by Bernard et al. (2001) which represents acidification problems in anaerobic reactors related with VFA accumulation, decreasing model complexity as well as the three-reaction model developed by Donoso-Bravo et al. (2009) for wastewater with a high fraction of particulate organic matter.

Odor formation due to hydrogen sulfide generation has caught the attention of the anaerobic digestion modelers. Hydrogen sulfide formation in sewage systems may occur in anoxic/anaerobic conditions in the reactor, piping, or pumping tanks by the action of sulfate reducing bacteria (Lomans et al. 2002; Sharma et al. 2008; Vollertsen et al. 2008). Current odorants compounds generation models explain some of the odor-promoting substances responsible for odor emissions (Parker and $\mathrm{Wu}$ 2006; Sharma et al. 2008). These models provide a general framework for odor abatement strategies, although they only consider chemical concentration of odor-promoting substances.

The main mechanisms of hydrogen sulfide formation correspond to two degradations routes: sulfate reducing bacteria action and amino acids transformation. Sulfate reducing bacteria use both the sulphate contained in the media and the VFA as substrates for growth. Thus, sulfate reducing bacteria can compete with methanogenic archaeas for carbon source (VFA) and electron donor, such as hydrogen sulfide, which may lead to the inhibition of the methanogenic stage (Kalyuzhnyi et al. 1998; Chen et al. 2008; Chou et al. 2008). This mechanism is important when treating salty wastewaters or with high level of soap waste. The protein degradation path is more important in the treatment of livestock wastewater (Peu et al. 2012). Methionine has been reported as the main precursor amino acid in hydrogen sulfide generation (Derbali 
et al. 1998; Du and Parker 2012). There are several kinetic expression for this process in the literature, for which some authors have used first-order rate (Du and Parker 2012) whereas others consider Monod kinetic (Mu et al. 2008; Ramirez et al. 2009).

Many authors have used hydrogen sulfide as a tracer compound to predict the odor intensity estimated from its chemical concentration, for instance using Steven's law (Gostelow et al. 2001; Stuetz and Frechen 2001; Hvitved-Jacobsen et al. 2002; Peu et al. 2012).

\subsection{Settling and Thickening Tanks}

Settling process allows the separation of the solids contained in the wastewater from the liquid phase. These solids are basically inorganic and organic matter, which settle in high solid content solution in both primary and secondary settlers. The solid particles fall down toward the bottom of the settler and accumulate in the lower part, developing anoxic/anaerobic conditions that promote odor formation and emission, if solids removal is not fast enough (Stellacci et al. 2010).

Sludge handling treatment has been reported as the major emission source of nuisance in WWTPs, containing tenths of different compounds, e.g., VOSCs, VOCs, VFA, $\mathrm{H}_{2} \mathrm{~S}, \mathrm{NH}_{3}$, etc. (Bonnin et al. 1990; Gostelow et al. 2001; Hvitved-Jacobsen et al. 2002; Muezzinoglu 2003; Sironi et al. 2006; Capelli et al. 2011; Jeon et al. 2009; Lebrero et al. 2013; Lebrero et al. 2011). In most cases, formation of malodor compounds can be reached by proliferation of anoxic or anaerobic conditions (Hvitved-Jacobsen et al. 2002). These conditions can be achieved during settling and/or thickening process when the SRT is not the appropriate, as a consequence of lower sludge removal rate. Under these conditions, the fermentation of the remaining organic matter produces VOCs and sulfate reducing bacteria generate sulfide compounds in the water phase, which is transferred through the interface water-air layer and then directly emitted to the atmosphere (Vollertsen et al. 2008). For this reason, the dynamics behavior modeling of these units can help to avoid anoxic/anaerobic environment.

The most widely used mathematical representation of the secondary settler, both in published studies and commercial software environments, was developed by Takács et al. (1991). The traditional "tanks- in-series" formulation amounts to a discretization of the mass balance partial differential equation (PDE) with a first-order finite volume method. The settler is spatially discretized into $n$ layers, on which a mass balance is calculated, with the numerical concentration corresponding to the middle of each layer (David et al. 2006). In that sense, David et al. (2009) highlighted several drawbacks of this model, in particular the fact that the number of discretization layers is used as a model parameter in order to match the experimental observations. Indeed, a typical number of ten layers are used to introduce numerical diffusion and smooth off the concentration profiles. The main drawback of models based on the discretization of first-order partial PDEs is that they cannot predict continuous variation of concentration with settler/thickener depth (Hamilton et al. 1992).

An integration of the activated sludge reactor model with a PDE settling model including biological reactions was developed by Hamilton et al. (1992). It was concluded that omission of bioreactions that take place in the settler increases the nitrate-nitrogen level in the effluent by about $1 \mathrm{~g} \mathrm{~m}^{-3}$ instead of a lower value considering the microbial removal action. The main advantage of this dynamic model is that it allows division of the settler into a considerably larger number of layers; thereby if a sufficient number of layers are used, the model successfully predicts the blanket level of the settler.

Recent studies have focused on using PDE mass balances for the secondary settler to describe dynamic behavior of these units. David et al. (2009) concluded that PDE model is very efficiently solved and produces realistic concentration evolutions, opening a new way for further investigations in settling modeling.

\section{Integrated WWTP Process Modeling}

For the entire WWTP simulation, two general approaches have been used either using separated models (which were developed for the different process units) that are connected to simulate the whole plant, or using a single and general model for the whole plant.

The first approach, namely interfaces approach, is based on the use of different models to simulate different treatment units. Since the state variables of 
each model are different, the construction of artificial interfaces between the existing standard unit-process models is required. The second approach is based on the construction of the so-called general model, which includes all the state variables and transformations needed to reproduce every process that takes place in the plant. In this type of models, the same components (the state variables) and transformations are used to simulate every process unit of the WWTP; therefore, specific interfaces, which connect different unit-process models, are not required. General models consider that both anaerobic and aerobic bacteria can proliferate in all the process units (Ruano et al. 2012).

The Biological Nutrient Removal Model No. 1 (BNRM1) (Seco et al. 2004) is classified as a general model. This model has been developed as a unique model to simulate the most important physical, chemical, and biological processes taking place in a WWTP. The model is based in ASM2d model (Henze et al. 1999) for the microbial activity in the WWTP secondary biological treatment, Takac's model (Takács et al. 1991) for the settling and thickening processes, and the ADM1 model (Batstone et al. 2002) for the anaerobic sludge treatment. This model does not include odor precursors formation, as exposed before, being necessary a modification for odor management tasks.

The Combined Activated Sludge-Anaerobic Digestion Model (CASADM) was developed to explain an alternative WWTPs process where the anaerobic effluent is linked with the conventional recirculation stream from the secondary clarifier and the settling tank (Young et al. 2013). This integrated model includes the anaerobic stage during the settling of the sludge, which represents an important contribution knowing that other models usually neglect these biological reactions.

In the literature, it is possible to find models for different processes, but each one is based on particular and specific state variables. The connection between models is a useful tool to expand the system limits results and also for process optimization (Benedetti et al. 2004) because the optimal management of the individual components of the system does not necessarily yield optimal performance of the entire system (Fronteau et al. 1997).

Ad hoc solutions were typically derived to circumvent the following three problems that occur when one tries to link existing, state-of-the-art models, which were originally developed in isolation (Vanrolleghem et al. 2005),

- Some state variables used in one model do not exist in the connected model.

- The meaning of a state variable in one system may not hold for the other system (e.g., components can be considered as inert in one system but may be biodegradable in another one).

- The elemental composition of a component in one model may not be identical for the connected model and, in some instances, the elements considered are not the same (e.g., in ASM3 COD, $\mathrm{N}$ and charge are considered; whereas in ADM1 $\mathrm{COD}, \mathrm{C}$ and $\mathrm{N}$ are taken into account).

A general framework using the Petersen and composition matrix was provided by Vanrolleghem et al. (2005). This methodology is friendly to the modelers because they are familiar with these matrixes.

However, if the odor formation is an important task for the plant management, these models do not provide any information about it. Due to the fact that previous models are built for other operational objectives, COD removal, biomass inhibition, oxygen consumption, biogas production, etc. Thereby, it is necessary to develop a WWTP dynamic odor model to describe and predict the odorants formation as well as their interaction in the mixed emission, including the meteorological influence on the odorants atmospheric diffusion.

\section{Atmospheric and Dispersion Models}

Modeling the odor dispersion from a source needs the characteristics of the emissions but also the meteorological conditions, typically wind speed and direction and atmospheric stability (De Melo Lisboa et al. 2006). Atmospheric conditions play an important role in odor dispersion as shown (Maïzi et al. 2010) with the high influence of the wind speed in the odor released from WWTP.

An atmospheric model is a mathematical representation of the dynamical processes, physical, chemical, and radiative, producing in the atmosphere. The ordinary differential equations (ODE) represent mathematically the time dependence of the processes. 
However, the partial differential equations (PDE) are used to describe time and space-dependent processes. These equations systems are usually replaced by mathematical approximations in order to solve and reduce the simulation time (Jacobson 2005).

A particular case of atmospheric model is the meteorological model, which excludes chemical transformations in the atmosphere (Souto et al. 2009). A meteorological forecast model is a model that is used to obtain weather prediction. Forecast models are usually validated with real data, observed data from meteorological stations, recording typical weather variables including wind speed, wind direction, pressure, temperature, relative humidity, and rainfall (Jacobson 2005). The main characteristics of 18 common meteorological models for numerical weather predictions used can be found in Kukkonen et al. (2012).

MM5 model is the widely used mesoscale model in forecast research topic, allowing nesting domains to achieve better resolution results. Nowadays, scientific community is moving from MM5 to weather research forecast (WRF) because of better effective resolution algorithm, less smoothing in the results reflecting better the influence of the terrain in the numerical weather results (Bowman 2009).

Commonly, the output of the forecast models are used as input by meteorological diagnostic models to achieve better grid resolution because the results for complex terrain has not enough accuracy (Hu et al. 2010). Diagnostic models do not provide any information about prognostic or future meteorological behavior, but perform a new high-resolution vector wind field that can be compared with real observation data from meteorological stations for validation. The build up of the high-resolution wind field can be done by two different approaches, interpolation by square distance of observed data or reparameterization solving again the motion equations (Wang et al. 2008).

Dispersion models describe the motion of the emitted pollutants from a specific source, being a macroscopic interpretation of the microscopic advection phenomena. Regulatory models are the most common used methodologies in order to describe and solve the dispersion equation, using algebraic equations, generally based on the Gaussian approximation for the vertical and horizontal concentration profiles.
In the literature, there are available many different dispersion models, changing their application, accuracy, model definition, resolution, etc. (Souto et al. 2001). More detailed information about these models can be found in Holmes and Morawska (2006).

Although odorant dispersion processes in the atmosphere is not different to other chemical species, some characteristics of the odorant dispersion problem drove to new and adapted odorant dispersion models. As the main characteristics,

- Processes scales are usually shorter in most of odorant dispersion problems.

- Because of that, odorant concentrations must be computed in very short periods; alternatively, peak and mean odorant concentrations are computed.

- Although chemical dispersion models usually compute pollutants concentrations, in the case of odorants, odor index is required. In fact, some odor dispersion models can compute the environmental odor based on odor emissions.

Considering these characteristics, a wide list of odor dispersion models were developed and applied. The application of odor nuisance estimation was previously discussed by Simms et al. (1999), considering ADMS model. Ormerod (2001) discussed the requirement of nonsteady conditions in odor dispersion modeling, with KSP model (Yamartino et al. 1996). Schauberger et al. (2000) presented the dynamic Gaussian Austrian Odor Dispersion Model (AODM) and its application to the microscale impact (tenths to hundred meters) of livestock emissions over residential areas. More recently, Piringer et al. (2012) analyzed the peak-to-mean relationship in odor dispersion modeling, using AODM and AUSTAL2000 models. This issue was also previously highlighted by Savunen and Rantakrans (2000) in their odor plume dispersion model.

Regulatory air pollution dispersion models provide a common and well-supported approach to simulate air pollutants dispersion. Some environmental agencies, as US EPA, try to support the availability of regulatory models, with the state-of-art and the best input datasets, in order to provide the best tools, also in odor dispersion. For instance, Sheridan (2004) and Hayes et al. (2006) applied ISCST US EPA regulatory model (USEPA 1997) to the odor impact of poultry farms emissions in Ireland. 
ISCST regulatory model was swap by AERMOD (USEPA 2001) as a regulatory Gaussian plume model. AERMOD is a steady-state plume model that incorporates air dispersion based on planetary boundary layer turbulence structure and simple/complex terrain effect. The total concentration at the receptor is calculated as the sum of the direct plume $\left(\mathrm{C}_{d}\right)$, indirect source $\left(\mathrm{C}_{p}\right)$, and the penetrate source $\left(\mathrm{C}_{r}\right)$,

$C(x, y, z)=C_{d}(x, y, z)+C_{p}(x, y, z)+C_{r}(x, y, z)$

However, as a steady-state model, AERMOD requires the application of approaches to estimate peak-to-mean relationship. On the other hand, the CALPUFF US EPA regulatory model (Scire et al. 1998) is a multilayer, multispecies nonsteady-state, Lagrangian, Gaussian, puff dispersion model that simulates the effects of time and space varying meteorological conditions on pollutants transport, transformation, and removal. It contains modules for complex terrain, over-water transport, and coastal influence. The total concentration at a receptor is obtained as the sum of the contributions of all nearby puffs averaged,

$C(x, y, z, t)=\sum_{\text {puff }=1}^{\text {totalpuffs }} C_{p u f f}(x, y, z, t)$

With environmental odorants, chemical concentrations are calculated and odor index can be derived from Stevens Law (Stevens 1960) calibrated to odor sensitivity. Also, CALPUFF is able to quantify directly odor dispersion in odor index, when just odor emissions are available, considering that odorants chemical transformation is neglected.

Generally, AERMOD tends to over predict the concentrations downwind, higher values than CALPUFF, which provides a better result for complex building/terrain. However, if the receptor is closer to the source, AERMOD do not represent properly the interaction between the plume and the complex structures dominates the plume path and its dispersion (Vieira de Melo et al. 2012). In the case of CALPUFF, as a nonsteady and three-dimensional model, it is possible to achieve better results using very high-resolution meteorological data (tenths to hundreds of meters)
(Souto et al. 2014). In spite of those problems, both models were applied to odor dispersion modeling worldwide, as in Jeong (2011) and Busini et al. (2012).

\section{Critical Discussion}

The unpleasant odor emissions modeling from WWTPs are an important issue due to complaints of the citizens and government concern, which has led to the generation of a series of new mandatory regulations.

Regulatory approved and recommended air emission models developed for WWTPs are mainly based on steady-state operation, neglecting dynamics changes during daily, weakly, or monthly plant operation, i.e., inlet streams, maintenance activities, or environmental conditions. It is necessary to improve this topic in order to represent with better accuracy the microbial changing dynamics developed inside the processes.

The use of dynamic operational modeling allows achieving better results related with odor assessment and management, increasing the process behavior knowledge. Atmospheric dynamics is also important to be considered and even incorporated inside the air emission model to predict the emissions rates depending on changing meteorological circumstances.

Nowadays, the more innovative techniques for odor monitoring are based on linking the dynamic olfactometry with the chemical analysis using GC-MS or e-noses. The main drawback of GC-MS-O is the high price and the difficulty for obtaining real-time data. Instead, the e-noses are a promising technique to monitor online; nonetheless, but actually these devices are built ad hoc for specific industrial applications, which does not enable a global chemical-odor correlation.

Atmospheric conditions have a strong relationship with the air emission impact, being favorable decreasing the impact during periods of high atmospheric instability (high wind speed, low pressure, and absence of thermal inversion). Several meteorological models contrasted and validated are available for the international scientific community in order to provide quality weather forecast (Kukkonen et al. 2012).

Dispersion models combine meteorological conditions, terrain description, and source emissions to provide the impact of emission, also considering chemical 
and physical processes within the plume. Apart from the different dispersion models previously referred, Holmes and Morawska (2006) published a review with the dispersion models available and its application to the pollutants dispersion; they concluded the necessity of achieving more information related with the boundary surface layer behavior concerning the pollutants dispersion for nearby receptors because of the significance of surface meteorological conditions in odor dispersion.

\section{Conclusions and Future Perspectives}

This review presents an integral view of the odor modeling problem in WWTPs. The information regarding odor formation, sources, measure, characterization, impact assessment, process modeling, weather forecast, and dispersion modeling is rather sparse in literature.

Future improvements in terms of odor characterization from these sources are needed to develop an accurate integrated dynamic odor-processes model. Unit model processes need to incorporate new features to provide a benchmark for quality odor emissions studies in WWTPs. New innovative analytical method, as GC-MS-O, e-noses, could provide better knowledge of these complex mixtures behavior. These new linked techniques could help to establish better correlations for odor emissions from their chemical concentration, decreasing analytical costs of olfactory measures.

Acknowledgments This paper/work was supported by CIRIC INRIA-Chile (EP BIONATURE) through Innova Chile Project Code: 10CE11-9157.

\section{References}

Adam, G., Lemaigre, S., Romain, A., Nicolas, J., Delfosse, P. (2013). Evaluation of an electronic nose for the early detection of organic overload of anaerobic digesters. Bioprocess Biosystems Engineering, 36(1), 23-33.

Albert, K.J., Lewis, N.S., Schauer, C.L., Sotzing, G.A., Stitzel, S.E., Vaid, T.P., Walt, D.R. (2000). Cross-reactive chemical sensor arrays. Chemical Reviews, 100(7), 2595-2626. doi:10.1021/cr980102w.

Donoso-Bravo, A., Retamal, C., Carballa, M., Ruiz-Filippi, G., Chamy, R. (2009). Influence of temperature on the hydrolysis, acidogenesis and methanogenesis in mesophilic anaerobic digestion: parameter identification and modeling application. Water Science and Technology, 60, 9-17.

Arshak, K., Moore, E., Lyons, G., Harris, J., Clifford, S. (2004). A review of gas sensors employed in electronic nose applications. Sensor Review, 24(2), 181-198. doi:10.1108/02602280410525977.

AUEPA (1999). National pollutant inventory: emission estimation technique manual for sewage and watewater treatment.

Batstone, D., \& Keller, J. (2003). Industrial applications of the iwa adm1. Water Science Technology, 47(12), 199-206.

Batstone, D., Keller, J., Angelidaki, I., Kalyuzhnyi, S., Pavlostathis, S., Rozzi, A., Sanders, W., Siegrist, H., Vavilin, V. (2002). The iwa anaerobic digestion model no 1 (adm1). Water Science Technology, 45(10), 65-73.

Batstone, D., Keller, J., Steyer, J. (2006). A review of adm1 extensions, applications, and analysis: 2002-2005. Water Science Technology, 54(4), 1-10.

Benedetti, L., Merilaen, J., Vanrolleghem, P. (2004). Model connectors for integrated simulations of urban wastewater systems. In Sewer networks and processes within urban water systems (pp. 13-20). IWA Publishing.

Bentley, R., \& Chasteen, T. (2004). Environmental voscs formation and degradation of dimethyl sulfide, methanethiol and related materials. Chemosphere, 55(3), 291-317.

Bernard, O., HadjSadok, Z., Dochain, D., Genovesi, A., Steyer, J. (2001). Dynamical model development and parameter identification for an anaerobic wastewater treatment process. Biotechnologica Bioengineering, 75(4), 424-438.

Bonnin, C., Laborie, A., Paillard, H. (1990). Odor nuisances created by sludge treatment: problems and solutions. Water Science Technology, 22(12), 65-74.

Bowman, C. (2009). Moving from mm5 to wrf In: Regional Smoke Management Meeting.

Busini, V., Capelli, L., Sironi, S., Nano, G., Rossi, A., Bonati, S. (2012). Comparison of calpuff and aermod models for odour dispersion simulation. Chemical Engineering Transactions, 30, 205-210. doi:10.3303/CET1230035.

Calbó, J., \& Baldasano, J. (1995). Prometeo: an hydrostatic mesoscale model applied to the simulation of land-sea breeze in the barcelona area. Environ Model Softw, 10(3), 139-155.

Capelli, L., Sironi, S., Del Rosso, R., Centola, P. (2009). Predicting odour emissions from wastewater treatment plants by means of odour emission factors. Water Resources, 43(7), 1977-1985.

Capelli, L., Sironi, S., Del Rosso, R., Céntola, P., Rossi, A., Austeri, C. (2011). Odour impact assessment in urban areas: case study of the city of terni. Procedia Environmental Science, 4, 151-157.

Capelli, L., Sironi, S., Del Rosso, R., Guillot, J.M. (2013). Measuring odours in the environment versus dispersion modelling: a review. Atmospheric Environment, 79, 731743.

Challenger, F. (1959). Aspects of the organic chemistry sulfur.

Chen, Y., Cheng, J., Creamer, K. (2008). Inhibition of anaerobic digestion process: a review. Bioresources Technology, 99(10), 4044-64.

Chou, H., Huang, J., Chen, W., Ohara, R. (2008). Competitive reaction kinetics of sulfate-reducing bacteria and methanogenic bacteria in anaerobic filters. Bioresources Technology, 99(17), 8061-8067. 
Committee European Normalization C (2003). En13725: air quality determination of odour concentration by dynamic olfactometry.

David, R., Vande Wouwer, A., Saucez, P., Vasel, J. (2006). Classical models of secondary settlers revisited. Computer Aided Chemical Engineering, 21(C), 677-682.

David, R., Vasel, J., Vande Wouwer, A. (2009). Settler dynamic modeling and matlab simulation of the activated sludge process. Chemicalo Engineering Journal, 146(2), 174183.

De Melo Lisboa, H., Guillot, J., Fanlo, J., Le Cloirec, P. (2006). Dispersion of odorous gases in the atmosphere-part $\mathrm{i}$ : modeling approaches to the phenomenon. Science of the Total Environment, 361(1-3), 220-228.

Dentoni, L., Capelli, L., Sironi, S., Remondini, M., Torre, M., Riccó, I., Dematté, F., Zanetti, S., Grande, M. (2012). Electronic noses for the qualitative and quantitative determination of environmental odours. Chemical Engineering Research Design, 30, 211-216.

Derbali, E., Makhlouf, J., Vezina, L. (1998). Biosynthesis of sulfur volatile compounds in broccoli seedlings stored under anaerobic conditions. Postharvest Biology Technology, 13(3), 191-204.

Dincer, F., \& Muezzinoglu, A. (2007). Odor determination at wastewater collection systems: olfactometry versus $\mathrm{h} 2 \mathrm{~s}$ analyses. Water Air Soil Pollution, 35(6), 565-570.

Donoso-Bravo, A., Mailier, J., Martin, C., Rodríguez, J., Aceves-Lara, C., Wouwer, A. (2011). Model selection, identification and validation in anaerobic digestion: a review. Water Research, 45(17), 5347-5364.

Du, W., \& Parker, W. (2012). Modeling volatile organic sulfur compounds in mesophilic and thermophilic anaerobic digestion of methionine. Water Research, 46(2), 539546.

EPA (1995). Compilation of air pollutant emission factors.

Ferreira, V. (2012). Revisiting psychophysical work on the quantitative and qualitative odour properties of simple odour mixtures: a flavour chemistry view. part 1: intensity and detectability. a review. Flavour Fragrance Journal, 27(2), 124-140.

Flores-Alsina, X., Corominas, L., Snip, L., Vanrolleghem, P.A. (2011). Including greenhouse gas emissions during benchmarking of wastewater treatment plant control strategies. Water Research, 45(16), 4700-4710.

Fronteau, C., Bauwens, W., Vanrolleghem, P. (1997). Integrated modelling: comparison of state variables, processes and parameters in sewer and wastewater treatment plant models. Water Science and Technology, 35(5), 373-380.

Schauberger, G., Pringer, M., Petz, E. (2000). Diurnal and annual variation of the sensation distance of odour emitted by livestock building calculated by the Austrian odour dispersion model (AODM). Atmospheric Environment, 34(28), 4839-4851.

Gostelow, P., \& Parsons, S. (2000). Sewage treatment works odour measurement. Science and Technology, 41(6), 33-40.

Gostelow, P., Parsons, S., Stuetz, R. (2001). Odour measurements for sewage treatment works. Water Research, 35(3), 579-597.

Gujer, W., Henze, M., Mino, T., Loosdrecht, M. (1999). Activated sludge model no. 3. Water Science and Technology, 39(1), 183-193.
Hamilton, J., Jain, R., Antoniou, P., Svoronos, S., Koopman, B., Lyberatos, G. (1992). Modeling and pilot scale experimental verification for predenitrification process. Journal of Environmental Engineering, 118(1), 3855.

Hayes, E.T., Curran, T.P., Dodd, V. (2006). A dispersion modelling approach to determine the odour impact of intensive poultry production units in Ireland. Bioresource Technology, 97(15), 1773-1779. doi:10.1016/j.biortech.2005.09.019.

Henze, M., Grady, C., Gujer, W., Marais, G., Matsuo, T. (1987). A general model for single-sludge wastewater treatment systems. Water Research, 21(5), 505-515.

Henze, M., Gujer, W., Mino, T., Matsuo, T., Wentzel, M., Marais, G., Van Loosdrecht, M. (1999). Activated sludge model no.2d, asm2d. Water Science and Technology, 39(1), $165-182$.

Hobbs, P., Misselbrook, T., Noble, R., Persaud, K. (2002). Chemical indicators that indicate olfactory response from pig and chicken manure. In Proceedings of 10th annual conference of the RAMIRAN (Recycling of Agricultural, Municipal and Industrial Residues in Agriculture) and Network.

Hobson, J. (1995). The odour potential: a new tool for odour management. Water Environmental Journal, 9(5), 458463.

Holmes, N., \& Morawska, L. (2006). A review of dispersion modelling and its application to the dispersion of particles: an overview of different dispersion models available. Atmospheric Environment, 40(30), 5902-5928.

Hu, J., Ying, Q., Chen, J., Mahmud, A., Zhao, Z., Chen, S., Kleeman, M. (2010). Particulate air quality model predictions using prognostic versus diagnostic meteorology in central california. Atmospheric Environment, 44(2), 215226.

Hvitved-Jacobsen, T., Vollertsen, J., Yongsiri, C., Nielsen, A., Abdul-Talib, S. (2002). Sewer microbial processes, emissions and impacts.

Jacobson, M.Z. (2005). Fundamentals of atmospheric modeling, 2nd edition. Cambridge University Press.

Jeon, E., Son, H., Sa, J. (2009). Emission characteristics and factors of selected odorous compounds at a wastewater treatment plant. Sensors, 9(1), 311-329.

Jeong, S.J. (2011). CALPUFF and AERMOD Dispersion models for estimating odor emissions from industrial complex area sources. Asian Journal of Atmospheric Environment, 5(1), 1-7. doi:10.5572/ajae.2011.5.1.001.

Kalantar, J., Howell, S., Talley, N. (2002). Prevalence of faecal incontinence and associated risk factors an underdiagnosed problem in the australian community? Med J Aust, 176(2), 54-57.

Kalyuzhnyi, S., Vyacheslav, F., Lens, P., Hulshoff Pol, L., Lettinga, G. (1998). Mathematical modelling as a tool to study population dynamics between sulfate reducing and methanogenic bacteria. Biodegradation, 9(3-4), 187199.

Kukkonen, J., Olsson, T., Schultz, D., Baklanov, A., Klein, T., Miranda, A., Monteiro, A., Hirtl, M., Tarvainen, V., Boy, M., Peuch, V., Poupkou, A., Kioutsioukis, I., Finardi, S., Sofiev, M., Sokhi, R., Lehtinen, K., Karatzas, K., San José, R., Astitha, M., Kallos, G., Schaap, M., Reimer, E., Jakobs, 
H., Eben, K. (2012). A review of operational, regionalscale, chemical weather forecasting models in europe. Atmosphere Chemical Physics, 12(1), 1-87.

Lacey, R., Mukhtar, S., Carey, J., Ullman, J. (2004). A review of literature concerning odors, ammonia, and dust from broiler production facilities: 1 . odor concentrations and emissions. Journal Poultry Science, 13(3), 500-508.

Laing, D., Eddy, A., Best, D. (1994). Perceptual characteristics of binary, trinary, and quaternary odor mixtures consisting of unpleasant constituents. Physiology and Behavior, 56(1), 81-93.

Lebrero, R., Bouchy, L., Stuetz, R., Muñoz, R. (2011). Odor assessment and management in wastewater treatment plants: a review. Critical Review Environmental Science and Technology, 41(10), 915-950.

Lebrero, R., Rangel, M., Muoz, R. (2013). Characterization and biofiltration of a real odorous emission from wastewater treatment plant sludge. Journal of Environmental Management, 116, 50-57.

Lehtinen, J., \& Veijanen, A. (2011). Odour monitoring by combined tdgcmssniff technique and dynamic olfactometry at the wastewater treatment plant of low h2s concentration. Water, Air, and Soil Pollution, 218(1-4), 185196.

Liu, W., Bao, J., Zou, K., Li, C., Xu, Y., Wang, L. (2010). Dynamic olfactometer used as a professional nose. In 2010 IEEE international conference on robotics and biomimetics, ROBIO 2010 (pp. 1327-1330).

Lomans, B., Pol, A., Op den Camp, H. (2002). Microbial cycling of volatile organic sulfur compounds in anoxic environments. Water Science and Technology, 45(10), 5560.

Maïzi, A., Dhaouadi, H., Bournot, P., Mhiri, H. (2010). Cfd prediction of odorous compound dispersion: case study examining a full scale waste water treatment plant. Bioprocess and Biosystems Engineering, 106(1), 68-78.

Mantovani, A., Artoni, R., Barausse, A., Palmeri, L., Pittarello, A., Benzo, M. (2010). Modeling odour dispersion from composting plants: comparison with electronic nose measurements. In Chemical engineering transactions 23 (pp. 297-302). doi:10.3303/CET1023050.

Martin, F. (2007). Modeling air emissions from wastewater treatment operations.

McGinley, M., \& Sensory, S. (2008). Odor thresholds emission factors for common wwtp processes (pp. 1-18).

Mu, S., Zeng, Y., Wu, P., Lou, S., Tartakovsky, B. (2008). Anaerobic digestion model no. 1-based distributed parameter model of an anaerobic reactor: I. Model development. Bioresource Technology, 99(9), 3665-3675.

Muezzinoglu, A. (2003). A study of volatile organic sulfur emissions causing urban odors. Chemosphere, 51(4), 245252.

Muñoz, R., Sivret, E., Parcsi, G., Lebrero, R., Wang, X., Suffet, I., Stuetz, R. (2010). Monitoring techniques for odour abatement assessment. Water Research, 44(18), 51295149 .

NSWEPA (2001). Approved methods for the modelling and assessment of air pollutants in new south wales.

Ormerod, R. (2001). Improving odour assessment by using better dispersion models: some examples. Water Science and Technology, 9(44), 149-156.
Parker, W. (2005). Application of the adm1 model to advanced anaerobic digestion. Bioresource Technology, 96(16), 1832-1842.

Parker, W., \& Wu, G. (2006). Modifying adm1 to include formation and emission of odourants. Water Science and Technology, 54(4), 111-117.

Pérez, A., Cortina, J., Palacios, A., Gullón, M., Lazarova, V., Bouchy, L. (2012). Assesment of the odour footprint of an underground wwtp in barcelona (spain). Chemical Engineering Research and Design, 23, 201-206.

Persaud, K., \& Dodd, G. (1982). Analysis of discrimination mechanisms in the mammalian olfactory system using a model nose. Nature, 299(5881), 352-355.

Peu, P., Picard, S., Diara, A., Girault, R., Beline, F., Bridoux, G., Dabert, P. (2012). Prediction of hydrogen sulphide production during anaerobic digestion of organic substrates. Bioresource Technology, 121, 419-424.

Pinheiro, C., Rodrigues, C.M., Schäfer, T., Crespo, J.a.G. (2002). Monitoring the aroma production during wine-must fermentation with an electronic nose. Biotechnology and Bioengineering, 77(6), 632-640.

Piringer, M., Schauberger, G., Petz, E., Knauder, W. (2012). Comparison of two peak-to-mean approaches for use in odour dispersion models. Water Science and Technology, 7(66), 1498-1501. doi:10.2166/wst.2012.357.

Ramirez, I., Mottet, A., Carrere, H., Déléris, S., Vedrenne, F., Steyer, J. (2009). Modified adm1 disintegration/hydrolysis structures for modeling batch thermophilic anaerobic digestion of thermally pretreated waste activated sludge. Water Research, 43(14), 3479-3492.

Romain, A.C., Nicolas, J., Cobut, P., Delva, J., Nicks, B., Philippe, F.X. (2013). Continuous odour measurement from fattening pig units. Atmospheric Environment, 77, 935-942.

Ruano, M., Serralta, J., Ribes, J., Garcia-Usach, F., Bouzas, A., Barat, R., Seco, A., Ferrer, J. (2012). Application of the general model biological nutrient removal model no. 1 to upgrade two full-scale wwtps. Environmental Technology, 33(9), 1005-1012.

Savunen, T., \& Rantakrans, E. (2000). The description and application of an odour dispersion model. Springer US.

Scire, J., Strimaitis, D., Yamartino, R. (1998). A user's guide for calpuff dispersion model (version 5).

Seco, A., Ribes, J., Serralta, J., Ferrer, J. (2004). Biological nutrient removal model no.1 (bnrm1). Water Science and Technology, 50(6), 69-78.

Sharma, K., Yuan, Z., de Haas, D., Hamilton, G., Corrie, S., Keller, J. (2008). Dynamics and dynamic modelling of h2s production in sewer systems. Water Research, 42(10-11), 2527-2538.

Sheridan, B. (2004). A dispersion modelling approach to determining the odour impact of intensive pig production units in Ireland. Bioresource Technology, 91(2), 145-152. doi:10.1016/S0960-8524(03)00179-2, http://linkinghub. elsevier.com/retrieve/pii/S0960852403001792.

Siegrist, H., Vogt, D., Garcia-Heras, J., Gujer, W. (2002). Mathematical model for meso and thermophilic anaerobic sewage sludge digestion. Environmental Science and Technology, 36(5), 1113-1123.

Simms, K.L., Wilkinson, S., Bethan, S. (1999). Odour nuisance and dispersion modelling: an objective approach to a very subjective problem. http://www.cerc.co.uk. 
Sironi, S., Capelli, L., Céntola, P., Del Rosso, R., Il Grande, M. (2006). Odour emission factors for the prediction of odour emissions from plants for the mechanical and biological treatment of msw. Atmospheric Environment, 40(39), 7632-7643.

Smet, E., Van Langenhove, H., De Bo, I. (1999). The emission of volatile compounds during the aerobic and the combined anaerobic/aerobic composting of biowaste. Atmospheric Environment, 33(8), 1295-1303.

Souto, M.J., Souto, J.A., Perez-Muñuzuri, V., Casares, J.J., Bermudez, J.L. (2001). A comparison of operational lagrangian particle and adaptive puff models for plume dispersion forecasting. Atmospheric Environment, 35, 23492360 .

Souto, J.A., Hermida, M., Casares, J.J., Bermudez, J.L. (2009). SAGA: a decision support system for air pollution management around a coal-fired power plant. International Journal of Environment and Pollution, 38, 444-461.

Souto, J.A., Moral, C., Hernandez-Garces, A., Rodriguez, A., Saavedra, S., Casares, J.J. (2014). Simulation of plume dispersion using different stack configurations and meteorological inputs. International Journal of Environment and Pollution, (in press).

Stellacci, P., Liberti, L., Notarnicola, M., Haas, C.N. (2010). Hygienic sustainability of site location of wastewater treatment plants: a case study. i. estimating odour emission impact. Desalination, 253(1-3), 51-56.

Stevens, S.S. (1960). The psychophysics of sensory function. American Scientist, 48(2), 1498-1501.

Stuetz, R., \& Frechen, F. (2001). Odours in wastewater treatment measurement modelling and control. IWA Publishing.

Stuetz, R., Fenner, R., Engin, G. (1999). Assessment of odours from sewage treatment works by an electronic nose, h2s analysis and olfactometry. Water Research, 33(2), 453461.

Takács, I., Patry, G., Nolasco, D. (1991). A dynamic model of the clarification-thickening process. Water Research, 25(10), 1263-1271.

Tsai, C., Chen, M., Ye, A., Chou, M., Shen, S., Mao, I. (2008). The relationship of odor concentration and the critical components emitted from food waste composting plants. Atmospheric Environment, 42(35), 8246-8251.

USEPA (1997). Preferred and alternative methods for estimating air emissions from wastewater collection and treatment. Tech. rep.

USEPA (2001). Water9 software: User's guide. van Thriel, C., Schaper, M., Kiesswetter, E., Kleinbeck, S., Juran, S., Blaszkewicz, M., Fricke, H., Altmann, L., Berresheim, H., Bruning, T. (2006). From chemosensory thresholds to whole body exposures-experimental approaches evaluating chemosensory effects of chemicals. International Arch of Occupational and Environmental Health, 79(4), 308-321.

Vanrolleghem, P., Rosen, C., Zaher, U., Copp, J., Benedetti, L., Ayesa, E., Jeppsson, U. (2005). Continuitybased interfacing of models for wastewater systems described by petersen matrices. Water Science and Technology, 52.

Vieira de Melo, A., Santos, J., Mavroidis, I., Reis Junior, N. (2012). Modelling of odour dispersion around a pig farm building complex using aermod and calpuff. Comparison with wind tunnel results. Building and Environment, 56, 8 20.

Vollertsen, J., Nielsen, A., Jensen, H., Hvitved-Jacobsen, T. (2008). Modeling the formation and fate of odorous substances in collection systems. Water Environmental Research, 80(2), 118-126.

Wang, W., Shaw, W., Seiple, T., Rishel, J., Xie, Y. (2008). An evaluation of a diagnostic wind model (calmet). Journal of Climate, 47(6), 1739-1756.

Yamartino, R.J., Strimaitis, D.G., Scire, J.S., Insley, E., Spitzak, M. (1996). Final report on the phase i development of the kinematic simulation particle (ksp) atmospheric dispersion model. Tech. rep., Earth Tech report 1274-3, prepared for Free University of Berlin and Umweltbundesamt, Berlin, FRG.

Yang, G., \& Hobson, J. (2000). Odour nuisance_advantages and disadvantages of a quantitative approach. Water Science and Technology, 41(6), 97-106.

Young, M., Marcus, A., Rittmann, B. (2013). A combined activated sludge anaerobic digestion model (casadm) to understand the role of anaerobic sludge recycling in wastewater treatment plant performance. Bioresource Technology, 136, 196-204.

Zarra, T., Naddeo, V., Belgiorno, V., Reiser, M., Kranert, M. (2009). Instrumental characterization of odour: a combination of olfactory and analytical methods. Water Science and Technology, 59(8), 1603-1609.

Zhou, M., Gong, J., Yang, C., Pu, W. (2013). Simulation of the performance of aerobic granular sludge sbr using modified asm3 model. Bioresource Technology, 127, $473-481$. 